J. Electroanal. Chem., 240 (1988) 185-199

Elsevier Sequoia S.A., Lausanne - Printed in The Netherlands

\title{
THE KINETICS OF CHARGING AND DISCHARGING OF IRIDIUM OXIDE FILMS IN AQUEOUS AND NON-AQUEOUS MEDIA
}

PETER G. PICKUP ${ }^{\star}$ and VIOLA I. BIRSS

Department of Chemistry, University of Calgary, Calgary, Alberta T2N 1N4 (Canada)

(Received 16th January 1987; in revised form 29th June 1987)

ABSTRACT

Cyclic voltammetry and chronocoulometry have been used to investigate the kinetics of oxidation and reduction of electrochemically generated Ir oxide films in $\mathrm{H}_{2} \mathrm{SO}_{4}(\mathrm{aq})$, basic aqueous $\mathrm{LiClO}_{4}$ solutions and $\mathrm{LiClO}_{4}+$ acetonitrile solutions. In acidic aqueous solutions, the scan rate at which the main anodic peak potential begins to shift positively in cyclic voltammetry experiments has been used as a parameter to assess the charging and discharging kinetics of Ir oxide films grown under various conditions. In acidic and basic aqueous solutions, chronocoulometric measurements indicate that electron transport through the oxide is rate limiting for the main redox wave, whereas ion transport probably limits the charging/discharging kinetics in $\mathrm{LiClO}_{4}+\mathrm{CH}_{3} \mathrm{CN}$ solutions. In this non-aqueous medium, it appears that ca. $35 \%$ of the oxide sites charge and discharge approximately an order of magnitude more rapidly than the remaining sites.

\section{INTRODUCTION}

Numerous practical applications of electrochemically prepared iridium oxides in electrochromic displays and charge storage devices have prompted a number of groups to investigate the kinetics of charging and discharging of this oxide in various aqueous solutions [1-5]. These studies are also relevant to other potential applications of Ir oxide, such as in electrocatalysis [6] and intracortical neural prosthesis [7,8], which also involve charge transport through the oxide.

Ir oxide films contain fixed Ir sites which can be switched electrochemically between the black, electronically conducting $\operatorname{Ir}(\mathrm{IV})$ state and the colourless, insulating $\operatorname{Ir}(\mathrm{III})$ state as a function of potential [1]:

$\operatorname{Ir}(\mathrm{IV})$ oxide $\cdot x \mathrm{H}_{2} \mathrm{O}+e^{-}=\operatorname{Ir}(\mathrm{III})$ oxide $\cdot x \mathrm{H}_{2} \mathrm{O}$

\footnotetext{
"Present address: Department of Chemistry, Memorial University of Newfoundland, St. John's, Newfoundland A1B 3X7, Canada.

0022-0728/88/\$03.50 (C) 1988 Elsevier Sequoia S.A.
} 
Injection of electrons into the oxide in this way requires concurrent injection of cations from the electrolyte solution or ejection of anions from the oxide in order to maintain electroneutrality within the film. The nature of the ions involved in this reaction in various media has been the subject of some controversy $[1,9,10]$.

Gottesfeld and McIntyre [1] employed potential step techniques to investigate the kinetics of coloration (Ir(III) $\rightarrow \operatorname{Ir}($ IV) $)$ and bleaching $(\operatorname{Ir}(\operatorname{IV}) \rightarrow \operatorname{Ir}(\operatorname{III}))$ of $\operatorname{Ir}$ oxide in aqueous $\mathrm{Na}_{2} \mathrm{SO}_{4}$ at $\mathrm{pH}$ 3.5. Coloration was found to be much more rapid than bleaching. It was postulated that protons are required for bleaching and that the slowness of bleaching was therefore due to the low proton concentration in the solution.

Glarum and Marshall [2] carried out an ac impedance study of Ir oxide in various aqueous $\mathrm{H}_{2} \mathrm{SO}_{4}+\mathrm{Na}_{2} \mathrm{SO}_{4}$ and $\mathrm{HClO}_{4}+\mathrm{NaClO}_{4}$ solutions. The response was fitted to a diffusion model and it was concluded that the rate at which electrons move between lattice sites (which is equivalent to the mobility of reduced $\operatorname{Ir}(\mathrm{III})$ lattice sites) limited the response rate. The diffusion coefficient for charge transport through the oxide was found to increase greatly as the oxide was oxidized to the Ir(IV) state.

Conway and Mozota [3] and Burke and Whelan [4] investigated the scan rate and film thickness dependence of the cyclic voltammetric response of Ir oxide in $0.5 \mathrm{M}$ $\mathrm{H}_{2} \mathrm{SO}_{4}$. Burke and Scannell [5] carried out a similar study in basic solutions. Burke and co-workers $[4,5]$ concluded that electron transport through the oxide lattice was the rate limiting process in Ir oxide oxidation and reduction and proposed a model based on an electron hopping mechanism. The involvement of $\operatorname{Ir}(\mathrm{V})$ and /or $\operatorname{Ir}(\mathrm{VI})$ states of the oxide was postulated to account for the fact that oxidation of Ir oxide is more rapid than reduction.

We have been investigating the influence of oxide growth conditions on the electrochemistry of Ir oxide [11] and as part of this work, the kinetic measurements presented here were performed. One aim of this work was to compare the kinetic performance of Ir oxide films in different media and to compare films which were grown under a variety of conditions. Throughout this work, a major objective was to gain further insight into the mechanism of charge transport through Ir oxide films in different media.

\section{EXPERIMENTAL}

All electrochemical experiments were carried out in conventional three-compartment glass cells under argon at room temperature. The working electrode was $99.9 \%$ purity Ir wire (Johnson Matthey; $0.5 \mathrm{~mm}$ dia.). A full description of the electrode pretreatment procedure is given elsewhere [12]. All electrode areas used in this paper are geometric areas.

Oxide films were grown in $0.5 \mathrm{M} \mathrm{H}_{2} \mathrm{SO}_{4}$ by pulsing the potential between -0.26 and $+1.24 \mathrm{~V}$ vs. SSCE at $0.5 \mathrm{~Hz}$, unless otherwise stated [1,12]. Oxide quantities are given in terms of $\mathrm{mol} \mathrm{cm}^{-2}$ of $\operatorname{Ir}(\Gamma)$ throughout this paper. A $1 \mu \mathrm{m}$ thick $\operatorname{Ir}$ oxide film contains ca. $8 \times 10^{-7} \mathrm{~mol} \mathrm{~cm}^{-2}$ of Ir [11]. 
Counter electrodes were Pt gauze or wire and RHE, SCE, SSCE or $\mathrm{Ag} / \mathrm{Ag}^{+}$ reference electrodes were used. All potentials are quoted relative to the SSCE (236 $\mathrm{mV}$ vs. the SHE).

An EG\&G PARC 173 potentiostat was used with a PARC 175 Universal Programmer and a PARC 179 digital coulometer. Hewlett-Packard 7044A and 7090 A recorders were used. A locally built voltage integrater was used in some of the chronocoulometry experiments.

Aldrich Gold Label acetonitrile was dried over molecular sieves (Fisher; $0.4 \mathrm{~nm}$ ) before use, and $\mathrm{LiClO}_{4}$ (Fisher) was dried at $60^{\circ} \mathrm{C}$ in a vacuum. Other reagents were reagent grade (Fisher) or better and were used as received, and all water was triply distilled.

\section{RESULTS AND DISCUSSION}

Voltammetry in aqueous media

Figure 1 shows a series of voltammograms at various scan rates $(v)$ for a

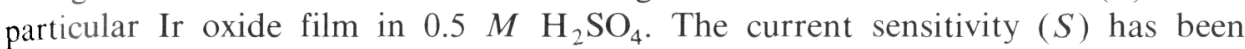
selected such that $S / v$ ( $\equiv$ current/sweep rate) is constant. This has been done because at low $v$, all currents are linearly proportional to $v$, and independent of solution stirring, indicative of the oxidation (and reduction) of a surface layer which is not under diffusion control. By plotting the voltammograms in this way, the effect of a wide range of $v$ can be seen in one figure.

In Fig. 1, the voltammogram at $5 \mathrm{mV} / \mathrm{s}$ shows the equilibrium response, i.e. no changes in the $S / v$ plot could be observed by reducing the scan rate any further.

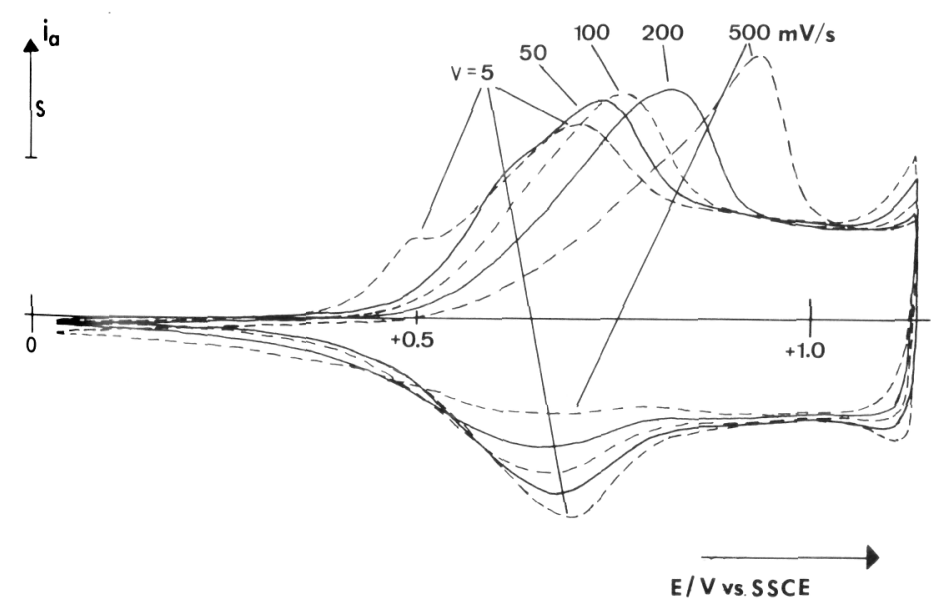

Fig. 1. Cyclic voltammograms at various scan rates $(v)$ of Ir oxide $\left(\Gamma=5.3 \times 10^{-7} \mathrm{~mol} / \mathrm{cm}^{2}\right)$ in $0.5 M$ $\mathrm{H}_{2} \mathrm{SO}_{4} \cdot \mathrm{S} / v=0.1\left(\mathrm{~mA} / \mathrm{cm}^{2}\right) /(\mathrm{mV} / \mathrm{s})$. 
Under these conditions, each potential can be considered an equilibrium potential, defining a particular extent of oxidation of the Ir oxide film. The peak potential (ca. $0.7 \mathrm{~V}$ vs. SSCE in Fig. 1), which is invariant with $v$ at $v \leqslant 5 \mathrm{mV} / \mathrm{s}$, can be termed the formal potential of the $\operatorname{Ir}(\mathrm{III} / \mathrm{IV})$ reaction $\left(E^{\circ \prime}\right)$ and could be considered to define an oxide film which has an equal number of $\mathrm{Ir}^{3+}$ and $\mathrm{Ir}^{4+}$ sites.

At scan rates greater than $5 \mathrm{mV} / \mathrm{s}$ (Fig. 1), the anodic peak shifts positively and the anodic peak current increases more than linearly with increasing $v$. The cathodic peak shifts slightly negatively and the cathodic peak current increases less than linearly with increasing $v$. Although it is clear that the voltammograms shown in Fig. 1 contain kinetic information, it is difficult to obtain quantitative kinetic parameters from this data.

Burke and Whelan [4] applied the semi-infinite linear diffusion equation for the variation of peak current $\left(i_{\mathrm{p}}\right)$ with scan rate $(v)$

$i_{\mathrm{p}}=2.7 \times 10^{5} n^{3 / 2} A D_{\mathrm{CT}}^{1 / 2} c_{0} v^{1 / 2}$

to the Ir oxide cyclic voltammograms, assuming the reaction is reversible, where $n$ is the number of electrons transferred per reacting species, $A$ is the electrode area, $D_{\mathrm{CT}}$ is the diffusion coefficient for charge transport and $c_{0}$ is the initial concentration of reacting species.

However, as is clear from Fig. 1, the fact that the $i-v$ curves are increasing with $v$, rather than decreasing with $v$, shows that $i_{\mathrm{p}}$ for the anodic peak does not depend linearly on $v^{1 / 2}$, as predicted by eqn. (1). Also, diffusion controlled reversible reactions are expected to yield peak potentials which are invariant with $v$, and this is clearly not observed here (Fig. 1). Even if the reaction were not fully reversible, in which case the peak (anodic) potential should move positively with increasing $v, a$ linear $i_{\mathrm{p}} / v^{1 / 2}$ relationship would still have been expected [13].

Equation (1) is known to yield inaccurate results for charge transport diffusion coefficients for polymer films [14]. The reason for this is that voltammetric waves for polymer films are generally broader than theory would predict [15] and therefore $i_{\mathrm{p}}$ is lower. Voltammetric waves for Ir oxide are similar in many ways to those for polymer films, but are particularly broad (peak width at half maximum $-300 \mathrm{mV}$ vs. a theoretical value of $91 \mathrm{mV}$ [15]) and therefore errors would be expected to be quite significant for this material. The breadth of the Ir oxide peak has at least two possible origins. First, it is likely that the envelope of charge from 0.3 to $1.0 \mathrm{~V}$ in Fig. 1 involves the overlap of at least two redox processes e.g. the $\operatorname{Ir}(\mathrm{III} / \mathrm{IV})$ process, and also the $\operatorname{Ir}(\mathrm{IV} / \mathrm{V}$ or $\mathrm{VI})$ reaction. In these films, it is also probable that not all sites react at exactly the same potential, and hence these reactions are spread out on the potential axis. Also, as the oxide is believed to contain various hydrated hydroxides and/or oxy-hydroxide species, it is feasible that lateral repulsive forces are present within the oxide structure, which is expected to lead to peak broadening [16].

In view of these difficulties with the application of eqn. (1) to the Ir oxide case, we have taken a different approach towards a kinetic interpretation of Fig. 1, which is an extension of an approach taken by Conway and Mozota [3]. It is clear from 


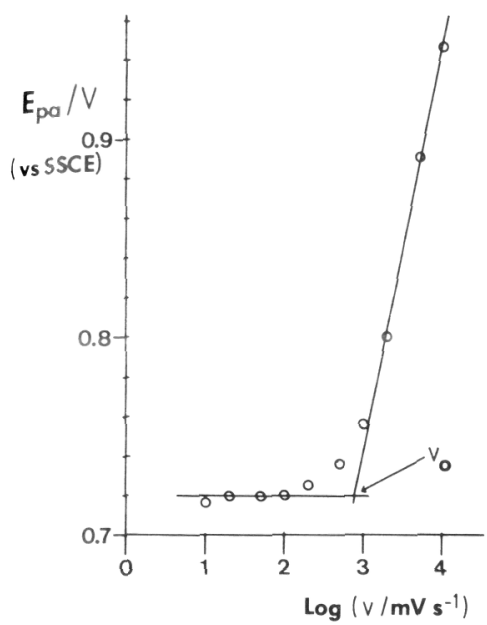

Fig. 2. Anodic peak potential $\left(E_{\mathrm{pa}}\right)$ vs. $\log \left(v / \mathrm{mV} \mathrm{s}^{-1}\right)$ for Ir oxide $\left(\Gamma=1.1 \times 10^{-7} \mathrm{~mol} / \mathrm{cm}^{2}\right)$ in $0.5 \mathrm{M}$ $\mathrm{H}_{2} \mathrm{SO}_{4}$.

Fig. 1 that the potential of the anodic peak $\left(E_{\mathrm{pa}}\right)$ is particularly sensitive to the scan rate $(v)$ at high $v$ but is insensitive to $v$ at low $v$. A typical plot of $E_{\mathrm{pa}}$ vs. $\log v$ (Fig. 2) exhibits two linear portions which intersect at a value of $v\left(v_{0}\right)$ which can be used as a measure of the kinetic response of the oxide film. $v_{0}$ is the scan rate beyond which the voltammogram changes from being reversible to being kinetically limited and is equal to $0.74 \mathrm{~V} / \mathrm{s}$ for the approximately $0.1 \mu \mathrm{m}$ thick oxide film used for Fig. 2. Clearly, the larger $v_{0}$, the more rapidly the Ir oxide film can charge and discharge reversibly. $v_{0}$ was originally derived from potentiodynamic sweep studies of monolayers at electrode surfaces [16]. In these cases, where a limited amount of charge can pass (one monolayer) in a particular range of potential, and where no diffusion limitations exist, $v_{0}$ can be related directly to $i_{0}$, the exchange current density, and hence to the standard rate constant of the reaction [16]. In the case of Ir oxide films, very similar behaviour is observed to that of monolayers, (e.g. linear $i / v$, invariant $E_{\mathrm{p}}$ and constant $Q$ at $v<v_{0}$ ) and hence the oxide can be considered to be similar to a surface layer having a hyper-extended area.

$v_{0}$ has been found in our work, and that of Conway and Mozota [3], to depend upon the thickness of the Ir oxide film, which can be varied by varying the length of time of potential pulsing. Figure 3 shows a plot of $\log v_{0}$ vs. $\log \Gamma$ for a number of Ir oxide films grown under a set of standard conditions (see figure legend) in $0.5 \mathrm{M}$ $\mathrm{H}_{2} \mathrm{SO}_{4} \cdot v_{0}$ decreases as the film thickness (or $\Gamma$ ) is increased.

The plot shown in Fig. 3 is useful for the assessment of the performance of Ir oxide films grown under different conditions. For example, the asterisk in the figure is a point for a film that was grown using a cycling frequency of $0.1 \mathrm{~Hz}$ instead of $0.5 \mathrm{~Hz}$. This oxide film was also conditioned after growth by cycling the potential between 0.5 and $1.5 \mathrm{~V}$ vs. RHE at $100 \mathrm{mV} / \mathrm{s}$ for $175 \mathrm{~min}$ which caused $E_{\mathrm{pa}}$ to shift 


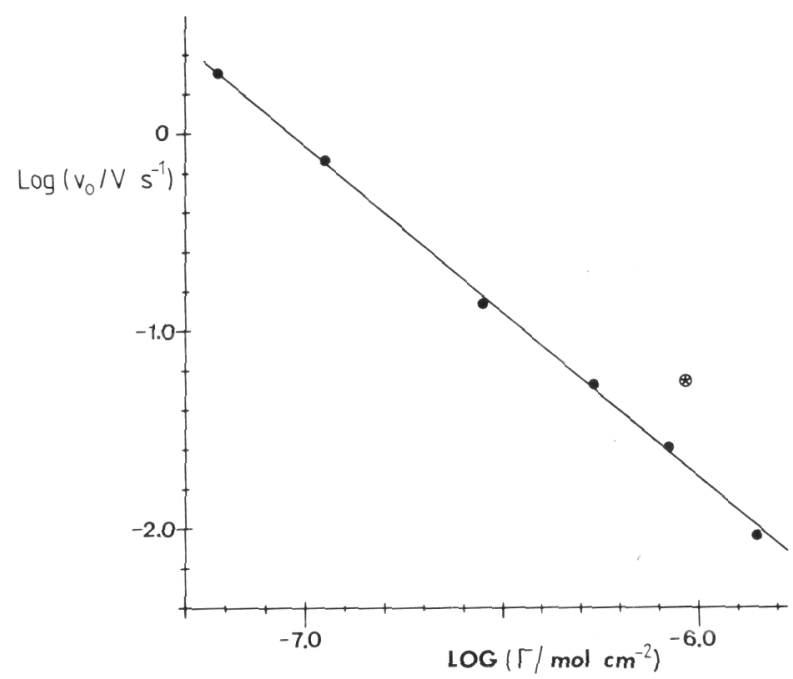

Fig. 3. $\log \left(v_{0} / \mathrm{V} \mathrm{s}^{-1}\right)$ vs. $\log \left(\Gamma / \mathrm{mol} \mathrm{cm}^{-2}\right)$ for Ir oxide films in $0.5 \mathrm{M} \mathrm{H}_{2} \mathrm{SO}_{4}$. Standard growth conditions: -0.26 to $+1.24 \mathrm{~V}$ potential pulsing at $0.5 \mathrm{~Hz}$ in $0.5 \mathrm{M} \mathrm{H}_{2} \mathrm{SO}_{4}$. Growth times in the range of 90 to $3600 \mathrm{~s}$.

in the negative direction by $50 \mathrm{mV} . v_{\mathrm{o}}$ is 2.7 times greater for this film than for a film of equal thickness grown under the standard conditions.

Overall, it can be said that $v_{0}$ is a useful empirical parameter which can be obtained from cyclic voltammetry and which can provide a comparative kinetic evaluation of Ir oxide films. However, it does not yield any insight into the mechanism of charge transport. This information could be more readily obtained from the dependence of peak position and size on $v$ when $v$ is greater than $v_{0}[3,16]$. Therefore, an understanding of why $E_{\mathrm{pa}}$ and $i_{\mathrm{p}}$ change with scan rate is obviously necessary.

A qualitative explanation of the scan rate dependence of the Ir oxide voltammograms has been given by Burke and Whelan [4]. These authors suggest that electrons are transported into or out of the oxide by a hopping mechanism in which an electron is exchanged between adjacent $\operatorname{Ir}($ III) and $\operatorname{Ir}(\mathrm{IV})$ sites. This electron hopping mechanism has been proposed earlier for the oxidation and reduction of other transition metal oxides, e.g. electron hopping between $\mathrm{Ni}^{2+}, \mathrm{Ni}^{3+}$ and $\mathrm{Ni}^{4+}$ sites in Ni oxide electrodes [17], and has been investigated in great detail for redox polymer coated electrodes [15]. In ref. 4, it was postulated that the generation of Ir(VI) sites at potentials positive of the main anodic peak enhances the electron hopping rate significantly.

How such a mechanism can lead to the voltammetric behaviour shown in Fig. 1 can be explained by analogy with charge transport through polymer films [18]. When a layer of poly-[Fe(vbpy) $]_{3}^{2+}\left(E^{\circ \prime}=0.92 \mathrm{~V}\right.$ vs. SSCE) (vbpy $=4$-methyl-4'vinyl-2,2'-bipyridine) is separated from the electrode by a layer of poly- 
$\left[\mathrm{Ru}(\mathrm{vbpy})_{3}\right]^{2+}$ having a higher $E^{\circ \prime}(1.14 \mathrm{~V}$ vs. SSCE), voltammetric curves very similar to those shown in Fig. 1 can be obtained [19]. The first anodic peak shifts in the positive direction and $i_{\mathrm{p}}$ increases more than linearly with increasing scan rate. The corresponding cathodic peak is broad and $i_{\mathrm{pc}}$ is much less than $i_{\mathrm{pa}}$. Its scan rate dependence is approximately that predicted for diffusion control ( $E_{\mathrm{p}} \cong$ constant, $\left.i_{\mathrm{p}} \propto v^{1 / 2}\right)$, as is that of the cathodic peak for Ir oxide.

For this polymer bilayer system, the charging and discharging of the outer polymer film is mediated by the inner film, which has the higher redox potential. This type of behaviour is also possible for homogeneous mixtures of sites with different redox potentials if the most easily oxidized component is either dilute or has a low electron self exchange rate [20].

For Ir oxide in $0.5 \mathrm{M} \mathrm{H}_{2} \mathrm{SO}_{4}$, it has been shown that at $0.92 \mathrm{~V}$ vs. SSCE, the average oxidation state of the Ir sites is $4+$ [11]. It can be seen from Fig. 1 that the Ir oxide is further oxidized (presumably to $\operatorname{Ir}(\mathrm{V})$ or $\operatorname{Ir}(\mathrm{VI})$ ) at potentials above 0.92 $\mathrm{V}$. Evidence for the presence of $\operatorname{Ir}(\mathrm{VI})$ species in these oxides, particularly in the surface region of relatively thick Ir oxide films, has been obtained using XPS [21]. Also the existence of $\mathrm{IrO}_{3}$ at the surface of Ir oxides formed by high temperature heating of Ir metal has been reported previously [22]. Clearly, the $\operatorname{Ir}(\mathrm{IV} / \mathrm{III})$ and $\operatorname{Ir}(\mathrm{VI} / \mathrm{V} / \mathrm{IV})$ waves overlap in Fig. 1 , and therefore, even at $0.92 \mathrm{~V}$, there must be a significant concentration of $\operatorname{Ir}(\mathrm{V})$ or $\operatorname{Ir}(\mathrm{VI})$ sites.

If electron hopping between these sites and Ir(III) or Ir(IV) sites is significantly faster than electron hopping between $\operatorname{Ir}(\mathrm{III})$ and $\operatorname{Ir}(\mathrm{IV})$ sites, then the type of behaviour observed with polymer bilayers could be expected at high scan rates. As the sweep rate is increased, the rate of electron hopping between the $\operatorname{Ir}$ (III) and Ir(IV) sites becomes insufficient to maintain equilibrium within the oxide and at any particular potential, fewer sites are in the $\operatorname{Ir}(\mathrm{IV})$ state than there would be at equilibrium. Once the potential is high enough to generate a significant concentration of $\operatorname{Ir}(\mathrm{V})$ and/or $\operatorname{Ir}(\mathrm{VI})$ sites, the charge transport rate increases as the remaining $\mathrm{Ir}^{3+}$ sites are rapidly oxidized to $\mathrm{Ir}^{4+}$ and the film reaches equilibrium. This results in an enhanced current at potentials positive of $E^{\circ}$. If equilibrium were not reached, then a significant portion of the charge due to film oxidation would pass in the potential range of the oxygen evolution reaction, and the observed charge in the range of potential from 0.5 to ca. $1.0 \mathrm{~V}$ (Fig. 1) would decrease. This is not observed. Increasing the scan rate increases the departure from equilibrium and therefore more $\operatorname{Ir}(\mathrm{V})$ and/or $\operatorname{Ir}(\mathrm{VI})$ sites, and hence a higher potential, are required to increase the electron hopping rate to attain equilibrium. Therefore, $E_{\mathrm{p}}$ shifts positively and $i_{\mathrm{pa}}$ can increase more than linearly with $v$.

The concept of mediated electron transport can also be used to explain some curious results that have been obtained with Ir oxide films which have been grown in solutions containing $1 \mathrm{M} \mathrm{LiClO}_{4}$. Figure 4 shows some voltammograms of Ir oxide in $0.1 M \mathrm{HClO}_{4}+1 \mathrm{M} \mathrm{LiClO}_{4}$ after various times of potential cycling between -0.2 and $+1.1 \mathrm{~V}$ after film growth. The initial $v_{0}$ for this film in this medium was $105 \mathrm{mV} / \mathrm{s}$, which is slightly higher than the value of $70 \mathrm{mV} / \mathrm{s}$ for a film of the same thickness in $0.5 \mathrm{M} \mathrm{H}_{2} \mathrm{SO}_{4}$. As the film was cycled between the 


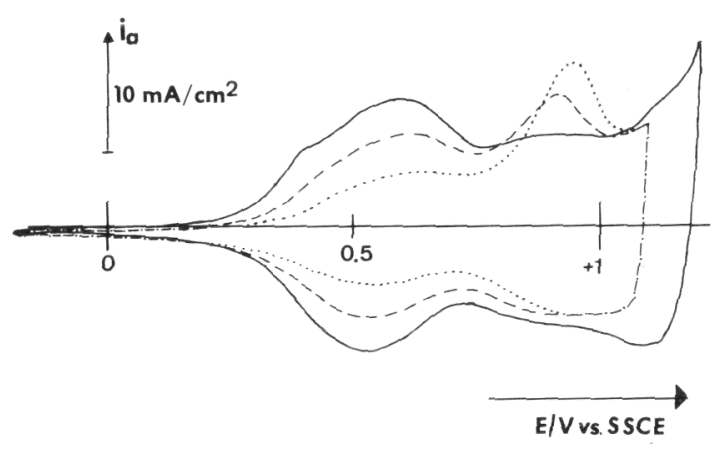

Fig. 4. Cyclic voltammograms $(100 \mathrm{mV} / \mathrm{s})$ of Ir oxide $\left(\Gamma=4.4 \times 10^{-7} \mathrm{~mol} / \mathrm{cm}^{2}\right.$; grown in $0.1 M$ $\mathrm{HClO}_{4}+1 \mathrm{M} \mathrm{LiClO}_{4}$ using -0.3 to $+1.2 \mathrm{~V}$ potential pulses at $0.5 \mathrm{~Hz}$ [11]) in $0.1 \mathrm{M} \mathrm{HClO}_{4}+1 \mathrm{M}$ $\mathrm{LiClO}_{4}$ after ca. 5 (- $(-), 35(\ldots-\ldots)$ and $170(\cdots \cdots)$ min of potential cycling between -0.2 and $+1.1 \mathrm{~V}$.

$\operatorname{Ir}(\mathrm{III})$ and $\operatorname{Ir}(\mathrm{IV} / \mathrm{V} / \mathrm{VI})$ states, the main anodic and cathodic peaks at $E^{\circ \prime}=0.56$ $\mathrm{V}$ diminished and a new irreversible anodic peak appeared at ca. 0.9 to $0.95 \mathrm{~V}$.

The position and scan rate dependence of this new peak at $-0.95 \mathrm{~V}$ suggests that it is due to $\operatorname{Ir}(\mathrm{V})$ or $\operatorname{Ir}(\mathrm{VI})$ mediated oxidation of the oxide, as discussed above. On the basis of this observation, a reasonable explanation for the behaviour of Ir oxides with time of potential cycling, shown in Fig. 4, is that the oxide film rearranges slowly, or "ages", to a form where electron hopping between some of the $\operatorname{Ir}(\mathrm{III})$ and $\operatorname{Ir}(\mathrm{IV})$ sites becomes slow. These sites appear to oxidize at a significant rate only when an adequate concentration of $\operatorname{Ir}(\mathrm{V})$ or $\operatorname{Ir}(\mathrm{VI})$ sites are generated at higher potentials.

Similar behaviour was observed when an Ir oxide film (grown in $1 \mathrm{M} \mathrm{LiClO}_{4}+$ $\mathrm{Na}_{2} \mathrm{~B}_{4} \mathrm{O}_{7}$ ) was cycled in $0.1 \mathrm{MLiOH}+1 \mathrm{M} \mathrm{LiClO}_{4}$ and then transferred to $0.5 \mathrm{M}$ $\mathrm{H}_{2} \mathrm{SO}_{4}$. The voltammetric response of this film in $0.5 \mathrm{M} \mathrm{H}_{2} \mathrm{SO}_{4}$ is shown in Fig. 5. $v_{0}$ for a film of this thickness, grown under standard conditions in $0.5 \mathrm{M} \mathrm{H}_{2} \mathrm{SO}_{4}$, would be ca. $20 \mathrm{mV} / \mathrm{s}$. Clearly, the film grown in basic $\mathrm{LiClO}_{4}$ has a much slower response with a $v_{0} \ll 5 \mathrm{mV} / \mathrm{s}$.

The very slow kinetics observed in these two experiments (Figs. 4 and 5) may involve the dehydration of the oxide in the $1 \mathrm{M} \mathrm{LiClO}_{4}$ solutions versus the situation in $\mathrm{H}_{2} \mathrm{SO}_{4}$. This suggestion is supported principally by the results of experiments in which Ir oxide films, formed in these two solutions, were subjected to a series of drying and weighing steps [11]. These experiments have indicated that Ir oxide films grown in $0.5 \mathrm{M} \mathrm{H}_{2} \mathrm{SO}_{4}$ contain more water than those grown in solutions containing $1 \mathrm{M} \mathrm{LiClO}_{4}$. In addition, it was observed that films grown in $\mathrm{H}_{2} \mathrm{SO}_{4}$ solutions crack more extensively in the vacuum chamber of a SEM, as compared to those grown in neutral solutions [11]. It is likely that this is also indicative of the presence of more water in the acid-grown films as compared to those formed in neutral $\mathrm{LiClO}_{4}$ solutions. The kinetic results imply that a lower 


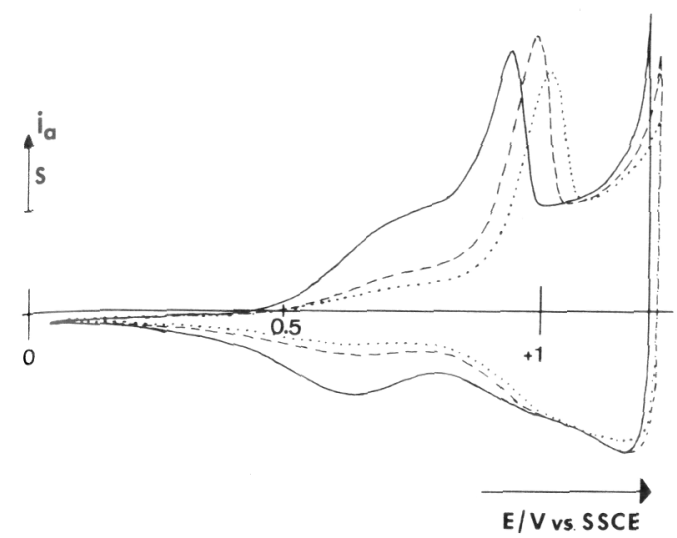

Fig. 5. Cyclic voltammograms in $0.5 \mathrm{MH}_{2} \mathrm{SO}_{4}$ of an Ir oxide film $\left(\Gamma=1.1 \times 10^{-6} \mathrm{~mol} / \mathrm{cm}^{2}\right)$ which was grown in $1 M \mathrm{LiClO}_{4}+0.01 \mathrm{M} \mathrm{Na}_{2} \mathrm{~B}_{4} \mathrm{O}_{7}$ using $0.5 \mathrm{~Hz}$ potential pulses between -1.2 and $+1.1 \mathrm{~V}$ [11] and cycled in $1 \mathrm{M} \mathrm{LiClO}_{4}+0.1 \mathrm{M} \mathrm{LiOH}$. Scan rate $=5(-), 50(--$,$) and 100(\cdots \cdots) \mathrm{mV} / \mathrm{s}$. $S / v=0.1\left(\mathrm{~mA} / \mathrm{cm}^{2}\right) /(\mathrm{mV} / \mathrm{s})$.

degree of hydration results in greater difficulty in either/both $\operatorname{Ir}(\mathrm{V}) / \operatorname{Ir}(\mathrm{VI})$ generation, or in electron hopping from $\operatorname{Ir}(\mathrm{III})$ and $\operatorname{Ir}(\mathrm{IV})$ to these sites.

\section{Chronocoulometry}

The rate of charging and discharging of Ir oxide films can be limited by either ion mobility in the film or electron mobility in the oxide or at the metal/oxide interface (reaction 1). Comparisons made of charge transport diffusion coefficients $\left(D_{\mathrm{CT}}\right)$ obtained in different media and over different potential ranges can provide valuable information regarding the identity of the rate limiting process [23].

$D_{\mathrm{CT}}$ can be measured in a chronocoulometric experiment in which the electrode potential is stepped from an initial potential $\left(E_{\mathrm{I}}\right)$ to a final potential $\left(E_{\mathrm{F}}\right)$ and the charge passed $(Q)$ is measured as a function of time. For diffusion controlled charge transport through a film of finite thickness, a plot of $Q$ vs. $t^{1 / 2}$ should be linear until $Q$ exceeds ca. $70 \%$ of the final charge [24]. $D_{\mathrm{CT}}$ is obtained from the slope of this linear portion of the plot by using eqn. (2) [24],

$Q=2 n F A\left(D_{\mathrm{CT}}\right)^{1 / 2} c t^{1 / 2} \pi^{-1 / 2}$

where $c$ is the concentration of sites $\left(\mathrm{mol} \mathrm{cm}{ }^{-3}\right)$ that are oxidized or reduced during the potential step, $n$ is the number of electrons involved in the electrochemical reaction and $A$ is the electrode area. $c$ can be determined from the total charge $\left(Q_{\mathrm{F}}\right)$ and the film thickness $(d)$ by using eqn. (3),

$c=Q_{\mathrm{F}} / n F A d$

$Q_{\mathrm{F}}$ was determined during the chronocoulometry experiment and $d$ was determined 

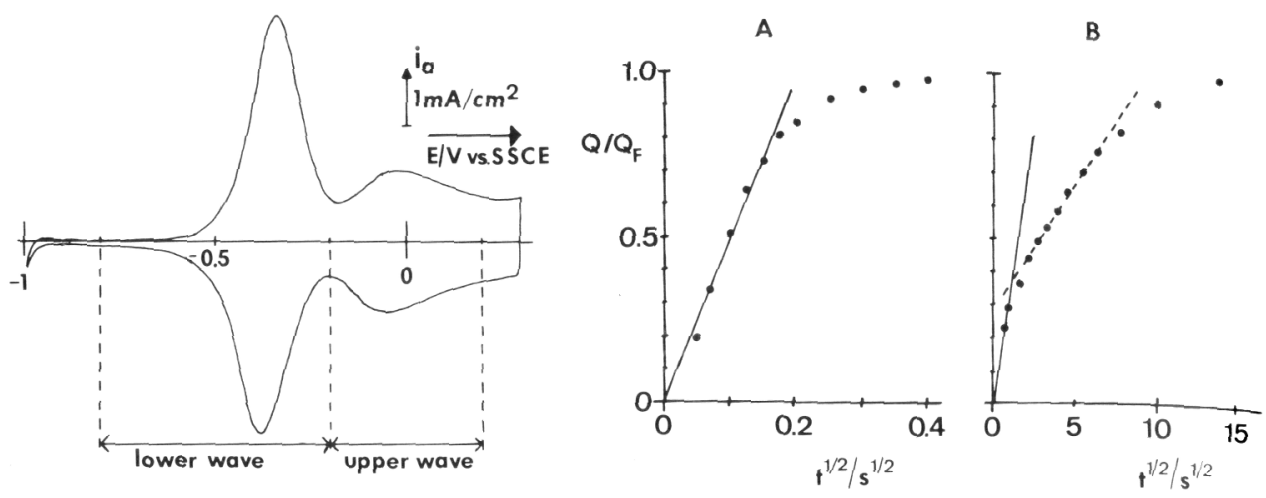

Fig. 6. Cyclic voltammogram $(10 \mathrm{mV} / \mathrm{s})$ of Ir oxide $\left(\Gamma=8.5 \times 10^{-7} \mathrm{~mol} / \mathrm{cm}^{2}\right)$ in $0.1 \mathrm{M} \mathrm{LiOH}+1 \mathrm{M}$ $\mathrm{LiClO}_{4}$.

Fig. 7. $Q / Q_{\mathrm{F}}$ vs. $t^{1 / 2}$ plots for discharge of $\mathrm{Ir}$ oxide in aqueous $0.1 M \mathrm{LiOH}+1 M \mathrm{LiClO}_{4}(\mathrm{~A}$ : $\Gamma=8.5 \times 10^{-7} \mathrm{~mol} / \mathrm{cm}^{2} ; E_{\mathrm{I}}=+0.2 \mathrm{~V}, E_{\mathrm{F}}=-0.2 \mathrm{~V}$ (upper wave, see Fig. 6)) and in acetonitrile containing $1 \mathrm{M} \mathrm{LiClO}_{4}\left(\mathrm{~B}: \Gamma=1.9 \times 10^{-6} \mathrm{~mol} / \mathrm{cm}^{2} ; E_{\mathrm{J}}=+0.61 \mathrm{~V}, E_{\mathrm{F}}=+0.21 \mathrm{~V}\right.$; see Fig. 8).Fig. 8 .

from the quantity of oxide ( $\Gamma$, determined by cyclic voltammetry [11]), assuming that a $1 \mu \mathrm{m}$ film contains $7.8 \times 10^{-7} \mathrm{~mol} \mathrm{~cm}^{-2}$ [11].

The measurement of charge transport diffusion coefficients by this method involves a number of significant errors which make the results accurate only to within a factor of 2 or 3 . A major cause of error results from uncertainty in the film thickness. Also, the uncompensated solution resistance, film inhomogeneity, concentration polarization in the solution, background currents and deviations from the simple diffusion equations can contribute to the error.

\section{Aqueous media}

In these experiments, Ir oxide charge/discharge behaviour was investigated in two separate regions of potential, which are referred to here as the lower and upper waves. The lower wave is the one centered at $+0.71 \mathrm{~V}$ in $0.5 \mathrm{M} \mathrm{H}_{2} \mathrm{SO}_{4}$ (Fig. 1) and at $-0.36 \mathrm{~V}$ in $1 \mathrm{M} \mathrm{LiClO}_{4}+0.1 \mathrm{M} \mathrm{LiOH}$ (Fig. 6). The upper wave refers to the region of the voltammograms which appears as a broad flat area centered at ca. $+0.95 \mathrm{~V}$ in $0.5 \mathrm{M} \mathrm{H}_{2} \mathrm{SO}_{4}$ (Fig. 1) and as the minor wave at $-0.02 \mathrm{~V}$ in $1 \mathrm{M}$ $\mathrm{LiClO}_{4}+0.1 M \mathrm{LiOH}$ (Fig. 6).

Figure 7A shows a typical $Q / Q_{\mathrm{F}}$ vs. $t^{1 / 2}$ plot for the reduction of Ir oxide in the upper wave in aqueous $1 M \mathrm{LiClO}_{4}+0.1 \mathrm{M} \mathrm{LiOH}$ solution. The plot is linear until the oxide is ca. $70 \%$ discharged and the diffusion coefficient was obtained from this linear portion. Similar plots are obtained for charging in the upper wave, for both charging and discharging in the lower wave and for analogous experiments in $0.5 \mathrm{M}$ $\mathrm{H}_{2} \mathrm{SO}_{4}$. Table 1 summarizes the charge and discharge diffusion coefficients obtained in aqueous media. Some of these diffusion coefficients were obtained by chronoamperometry, as indicated in the footnote of Table 1 [25]. It should be noted that 
TABLE 1

Charge and discharge diffusion coefficients for Ir oxide in aqueous media

\begin{tabular}{|c|c|c|c|c|c|c|}
\hline \multirow{3}{*}{$\begin{array}{l}\text { Exp. } \\
\text { no. }\end{array}$} & \multirow[t]{3}{*}{ Medium } & \multicolumn{4}{|c|}{$10^{8} \times$ Diffusion coefficient $/ \mathrm{cm}^{2} \mathrm{~s}^{-1}$} & \multirow{3}{*}{$\begin{array}{l}\text { Film } \\
\text { thickness } / \mu \mathrm{m}\end{array}$} \\
\hline & & \multicolumn{2}{|c|}{ Lower wave } & \multicolumn{2}{|c|}{ Upper wave } & \\
\hline & & Charge & Discharge & Charge & Discharge & \\
\hline$\widehat{1, b, c}$ & $0.5 \mathrm{M} \mathrm{H}_{2} \mathrm{SO}_{4}{ }^{\mathrm{d}}$ & & & 400 & $>400$ & -2 \\
\hline $2^{b}$ & $0.5 \mathrm{M} \mathrm{H}_{2} \mathrm{SO}_{4}{ }^{\mathrm{d}}$ & & & 30 & 30 & -10 \\
\hline $3^{b}$ & $0.5 \mathrm{M} \mathrm{H}_{2} \mathrm{SO}_{4}^{\mathrm{d}}$ & & & 10 & 20 & -10 \\
\hline $4^{a, e}$ & $0.5 \mathrm{M} \mathrm{H}_{2} \mathrm{SO}_{4}{ }^{\mathrm{d}}$ & 3 & 0.4 & 40 & 40 & -1 \\
\hline $5^{\text {a.e }}$ & $\begin{array}{l}1 \mathrm{M} \mathrm{LiClO}_{4}^{+} \\
0.1 \mathrm{M} \mathrm{LiOH}^{\mathrm{d}}\end{array}$ & 1 & 0.8 & 20 & 30 & -1 \\
\hline$b^{\text {a.e }}$ & $\begin{array}{l}1 M \mathrm{LiClO}_{4}+ \\
0.1 M \mathrm{LiOH}^{\mathrm{f}}\end{array}$ & 0.4 & 0.2 & 10 & 20 & -1 \\
\hline
\end{tabular}

a $I R_{\mathrm{u}}$ compensation used.

b Chronoamperometry.

c Oxide growth at $0.1 \mathrm{~Hz}$ (all other experiments done at $0.5 \mathrm{~Hz}$ ); potential cycled for long period of time before diffusion measurements made.

${ }^{d}$ Oxide grown in $0.5 \mathrm{M} \mathrm{H}_{2} \mathrm{SO}_{4}$.

'Chronocoulometry.

${ }^{f}$ Oxide grown in $1 M \mathrm{LiClO}_{4}+0.1 M \mathrm{Na}_{2} \mathrm{~B}_{4} \mathrm{O}_{7}$.

the diffusion coefficients are independent of the film thickness (Experiments 1-4), since the linear portion of the $Q$ vs. $t^{1 / 2}$ (or $I$ vs. $t^{-1 / 2}$ ) plots corresponds to the time before the concentration perturbation reaches the outer edge of the film $[24,25]$. This result does indicate, however, that there are no significant changes in the nature of the oxide films as they are made thicker.

In both $0.5 \mathrm{M} \mathrm{H}_{2} \mathrm{SO}_{4}$ and $1 \mathrm{M} \mathrm{LiClO}_{4}+0.1 \mathrm{M} \mathrm{LiOH}$, the diffusion coefficients for the lower wave are one to two orders of magnitude lower than those for the upper wave. Since the electronic conductivity of the oxide is known to decrease as the oxide is reduced $[2,26]$, these results suggest that the charging and discharging of Ir oxide in the lower wave in aqueous media is limited by the electronic conductivity of the oxide. It is unlikely that the ionic conductivity of the oxide would also change by several orders of magnitude between the upper and lower waves. It is not clear from the data in Table 1 which process is rate limiting for the upper wave. In this potential range, the electronic conductivity is high so it is possible that the ionic mobility is now rate limiting.

The extremely good kinetic performance of the electrode in Experiment 1 is due to the fact that this oxide was grown using a lower cycling frequency than was used in Experiments 2-6 $(0.1 \mathrm{~Hz}$ compared to $0.5 \mathrm{~Hz})$, and also that the potential was cycled extensively after oxide growth and prior to the kinetic experiment (see asterisk in Fig. 3). The fact that solution resistance compensation ( $I R_{\mathrm{u}}$ compensation) was not used in Experiments 2 and 3 is not a factor here. For such thick films, $I R_{\mathrm{u}}$ compensation was not needed, e.g. for the $1 \mu \mathrm{m}$ thick film, $I R_{\mathrm{u}}$ decreased the measured $D_{\mathrm{CT}}$ by only a factor of 2 . 
The chronocoulometric results obtained here for the kinetics of Ir oxide charging and discharging in $0.5 \mathrm{M} \mathrm{H}_{2} \mathrm{SO}_{4}$ are 1 to 3 orders of magnitude greater than those reported by Burke and Whelan [4]. Several factors can account for this. Firstly, Burke and Whelan investigated only the lower wave and therefore we cannot compare their results with ours for the upper wave. Secondly, we have compensated for the solution resistance in acquiring our results. This has been found to increase the observed $D_{\mathrm{CT}}$ values by a factor of ca. 2 . Thirdly, our oxide films were grown under potential pulsing rather than potential cycling conditions.

Even so, the results presented here support the conclusions of Glarum and Marshall [2] and Burke and Whelan [4], which state that charging and discharging of the main (lower) wave of Ir oxide in aqueous solutions is limited by electron mobility within the oxide. This has been indicated in our work by the large difference in the charging/discharging rates for the upper and lower redox waves, which correlates with the known increase in the electronic conductivity of the oxide aqueous solutions as it is oxidized.

\section{Non-aqueous media}

Figure 8 shows a typical voltammogram of an $\mathrm{Ir}$ oxide electrode in $1 \mathrm{M}$ $\mathrm{LiClO}_{4}+\mathrm{CH}_{3} \mathrm{CN}$. This $\mathrm{CV}$ can be referred to for the study of kinetics of Ir oxide charge and discharge in this medium. A detailed analysis of the electrochemistry of Ir oxide in $\mathrm{CH}_{3} \mathrm{CN}$ has been presented elsewhere [27].

Figure 7B shows a typical $Q / Q_{\mathrm{F}}$ vs. $t^{1 / 2}$ plot for the discharge (reduction) of Ir oxide in $1 \mathrm{M} \mathrm{LiClO}_{4}+\mathrm{CH}_{3} \mathrm{CN}$. The upper potential limit for this experiment $(+0.6$ V) was chosen because at higher potentials, a significant background current was observed. The lower potential limit $(+0.2 \mathrm{~V})$ corresponds to ca. $20 \%$ of full discharge from $+0.6 \mathrm{~V}$ (Fig. 8) and therefore this experiment is analogous to discharge of the upper wave in aqueous solutions. The plot shown in Fig. 7B does not have the same form as that in Fig. 7A for the discharge of the Ir oxide upper

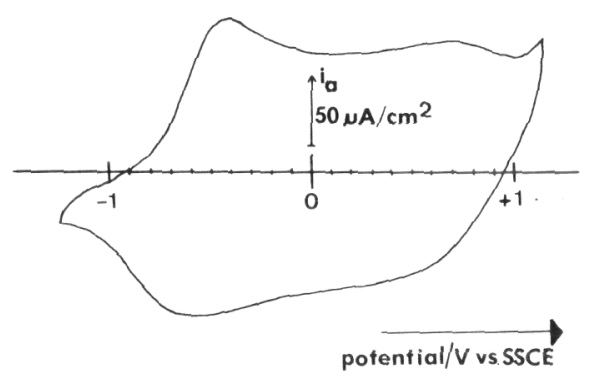

Cyclic voltammogram $(1 \mathrm{mV} / \mathrm{s})$ of Ir oxide $\left(\Gamma=1.9 \times 10^{-6} \mathrm{~mol} / \mathrm{cm}^{2}\right.$; grown in $1 \mathrm{M} \mathrm{LiClO}_{4}+0.01 \mathrm{M}$ $\mathrm{Na}_{2} \mathrm{~B}_{4} \mathrm{O}_{7}$ using $0.5 \mathrm{~Hz}$ potential pulses between -1.2 and $+1.1 \mathrm{~V}$ ) in acetonitrile containing $1 M$ $\mathrm{LiClO}_{4}$. 
wave in an aqueous solution. In Fig. 7B, at short times, Ir oxide film discharge is rapid and the slope (solid line) yields a diffusion coefficient of $0.5 \times 10^{-8} \mathrm{~cm}^{2} / \mathrm{s}$, which is higher than some of the figures in Table 1 for the lower wave in aqueous solutions. However, as oxide discharge progresses, the diffusion coefficient drops to a value of $0.06 \times 10^{-8} \mathrm{~cm}^{2} / \mathrm{s}$, given by the slope at longer times in Fig. 7B (dashed line). Therefore, it appears that at least two processes having different kinetic responses are involved in the discharge of $\mathrm{Ir}$ oxide in $1 \mathrm{M} \mathrm{LiClO}_{4}+\mathrm{CH}_{3} \mathrm{CN}$.

As a first model, it can be assumed that two different regions of the oxide film discharge at different rates in $\mathrm{CH}_{3} \mathrm{CN}$ solutions. Region I is discharged rapidly, whereas Region II is discharged more slowly. The initial slope of the $Q / Q_{\mathrm{F}}$ vs. $t^{1 / 2}$ plot (e.g. at $t<0.5 \mathrm{~s}$; solid line in Fig. 7B) and the slope at longer times (dashed line in Fig. 7B) yield diffusion coefficients for Regions I and II, respectively. The intercept of these two lines defines the proportion of the total oxide that discharges as Region I (i.e. - 35\%).

In order to investigate changes in charge/discharge kinetics as a function of the depth of discharge in this non-aqueous medium and to gain insight into the nature of the two regions, a series of potential step experiments were performed in which the lower potential limit was varied while the upper potential limit was kept constant at $+0.6 \mathrm{~V}$. Both charging and discharging experiments were performed and the depth of discharge over this range of potential was varied from 3 to $100 \%$. In all cases, the $Q / Q_{\mathrm{F}}$ vs. $t^{1 / 2}$ plots were similar to that shown in Fig. 7B. The diffusion coefficients for the two regions were constant within experimental error $\left(0.7 \pm 0.2 \times 10^{-8} \mathrm{~cm}^{2} / \mathrm{s}\right.$ for Region I, $0.06 \pm 0.01 \times 10^{-8} \mathrm{~cm}^{2} / \mathrm{s}$ for Region II $)$, as was the proportion of Region I ( $35 \pm 6 \%$ ).

The independence of the diffusion coefficients from the depth of discharge in both Regions I and II is strong evidence that ion mobility limits the discharge and charging rates of $\mathrm{Ir}$ oxide in $\mathrm{CH}_{3} \mathrm{CN}$. If electron movement were rate limiting, then the diffusion coefficient would be expected to decrease with increasing depth of discharge since, by analogy with the results in aqueous solutions $[2,26]$, the electronic conductivity of the oxide is expected to decrease as the oxide is discharged.

Without further information, the interpretation of the results involving two regions of the oxide can only be speculative. The nature of these two regions is not clear. It is possible that the oxide contains a mixture of relatively large channels and very small pores. The $\operatorname{Ir}(\mathrm{III} / \mathrm{IV})$ sites close to the channels might then charge and discharge rapidly (Region I), while those in the smaller pores might charge and discharge more slowly (Region II). It is also possible that charge and discharge of Region I is limited by the electronic conductivity of the oxide. The diffusion coefficients for this region are, within experimental error, the same as for the lower wave of Ir oxide in aqueous media where electron mobility is thought to limit the charge/discharge rate.

Another possible interpretation of the two regions within the Ir oxide film observed in $\mathrm{CH}_{3} \mathrm{CN}$ solutions is that one region is more hydrated than the other. The more hydrated region might be expected to be charged and discharged more rapidly than the less hydrated region. 
It is interesting that a kinetic response showing two regions of the Ir oxide film does not manifest itself in aqueous media. The oxide is probably highly hydrated in aqueous solutions and is likely to have a very open structure which permits rapid ion movement. In $\mathrm{CH}_{3} \mathrm{CN}$, the oxide is probably dehydrated and may have a less open structure which restricts ion movement.

\section{CONCLUSIONS}

Cyclic voltammetry and chronocoulometry have been utilized to study the kinetics of charge transport through electrochemically formed Ir oxide films. The cyclic voltammetric experiments have yielded a parameter, $v_{0}$, the scan rate beyond which the principal anodic peak begins to shift positively. $v_{0}$ is a useful parameter for comparing oxide films for their ability to charge and discharge reversibly. It has been shown to vary inversely with the amount of oxide present. At sweep rates greater than $v_{0}$, it is considered that the rate of electron hopping between the $\operatorname{Ir}(\mathrm{III})$ and $\operatorname{Ir}(\mathrm{IV})$ sites within the oxide film becomes insufficient to maintain equilibrium conditions. However, at higher potentials, the generation of further redox couples involving $\operatorname{Ir}(\mathrm{V})$ and/or $\operatorname{Ir}(\mathrm{VI})$ sites during $\operatorname{Ir}$ oxide oxidation enhance the charge transport rate by mediating $\operatorname{Ir}(\mathrm{III})$ oxidation.

Chronocoulometry was also utilized here in both aqueous and non-aqueous solutions in order to quantify Ir oxide charge and discharge kinetics. In both $0.5 \mathrm{M}$ $\mathrm{H}_{2} \mathrm{SO}_{4}$ and in aqueous $1 \mathrm{M} \mathrm{LiClO}_{4}+0.1 \mathrm{M} \mathrm{LiOH}$ solutions, the charge/discharge rates were determined separately over two ranges of potential (lower wave and higher wave). It was found that the rate of charge and discharge of Ir oxide in the main (lower) wave in these aqueous solutions is limited by electron mobility within the oxide and $D_{\mathrm{CT}}$ was found to be in the range of 0.2 to $3 \times 10^{-8} \mathrm{~cm}^{2} / \mathrm{s}$. In the upper wave, at more positive potentials, as the electronic conductivity of the oxide increases, the ionic mobility becomes rate limiting and $D_{\mathrm{CT}}$ is now found to be 10 to $40 \times 10^{-8} \mathrm{~cm}^{2} / \mathrm{s}$.

The kinetics of charging and discharging of $\mathrm{Ir}$ oxide films in a non-aqueous solution have been reported for the first time here. The results are significantly different than those for aqueous media in that two diffusion coefficients are obtained. Oxide charging and discharging rates now appear to be limited by ion (e.g. $\mathrm{Li}^{+}$) mobility in two different regions, or environments, within the oxide film. These may be structurally different, e.g. large channels vs. small pores, or they may vary in the degree of hydration.

\section{ACKNOWLEDGEMENT}

We gratefully acknowledge the financial support of Allied Canada Incorporated and the Natural Sciences and Engineering Research Council of Canada. 


\section{REFERENCES}

1 S. Gottesfeld and J.D.E. McIntyre, J. Electrochem. Soc., 126 (1979) 742.

2 S.H. Glarum and J.H. Marshall, J. Electrochem. Soc., 127 (1980) 1467.

3 B.E. Conway and J. Mozota, Electrochim. Acta, 28 (1983) 9.

4 L.D. Burke and D.P. Whelan, J. Electroanal. Chem., 162 (1984) 121.

5 L.D. Burke and R.A. Scannell, J. Electroanal. Chem., 175 (1984) 119.

6 J. Mozota and B.E. Conway, J. Electrochem. Soc., 128 (1981) 2142.

7 L.S. Robblee, J.L. Lefco and S.B. Brummer, J. Electrochem. Soc., 130 (1983) 731.

8 C.L. Ballestrasse, R.T. Ruggeri and T.R. Beck, Ann. Biomed. Eng., 13 (1985) 405.

9 G. Beni, C.E. Rice and J.L. Shay, J. Electrochem. Soc., 127 (1980) 1342.

10 P.G. Pickup and V.I. Birss, J. Electroanal. Chem., 240 (1988) 171.

11 P.G. Pickup and V.I. Birss, J. Electrochem. Soc., in press.

12 P.G. Pickup and V.I. Birss, J. Electroanal. Chem., 220 (1987) 83.

13 P. Delahay, New Instrumental Methods in Electrochemistry, Robert E. Krieger Publishing Co., Huntington, NY, 1980.

14 P.G. Pickup and R.A. Osteryoung, Inorg. Chem., 24 (1985) 2707.

15 R.W. Murray in A.J. Bard (Ed.), Electroanalytical Chemistry, Vol. 13, Marcel Dekker, New York, 1984, p. 191.

16 H.A. Kozlowska and B.E. Conway, J. Electroanal. Chem., 95 (1979) 1.

17 B.E. Conway and P.L. Bourgault, Can. J. Chem., 37 (1959) 292.

18 H.D. Abruna, P. Denisevich, M. Umana, T.J. Meyer and R.W. Murray, J. Am. Chem. Soc., 103 (1981) 1.

19 P.G. Pickup, C.R. Leidner, P. Denisevich and R.W. Murray, J. Electroanal. Chem., 164 (1984) 39 20 R.W. Murray, personal communication, 1985

21 J. Augustynski, M. Koudelka, J. Sanchez and B.E. Conway, J. Electroanal. Chem., 160 (1984) 233.

22 K.S. Kim, C.D. Sell, N. Winograd and M.W. Breiter, Electrochem. Soc. Softbound Proceedings Series, Electrochem. Soc., Princeton, NJ, 1974, p. 242.

23 P.G. Pickup and R.A. Osteryoung, J. Electroanal. Chem., 195 (1985) 271.

24 J.Q. Chambers, J. Electroanal. Chem., 130 (1980) 381.

25 P. Daum, J.R. Lenhard, D. Rolison and R.W. Murray, J. Am. Chem. Soc., 102 (1980) 4649.

26 S. Gottesfeld, J. Electrochem. Soc., 127 (1980) 1922.

27 P.G. Pickup and V.I. Birss, J. Electrochem. Soc., in press. 